- News \& Views •

\title{
Phase Two of the Integrative Monsoon Frontal Rainfall Experiment (IMFRE-II) over the Middle and Lower Reaches of the Yangtze River in 2020
}

\author{
Chunguang CUI ${ }^{1}$, Xiquan $\mathrm{DONG}^{* 2}$, Bin $\mathrm{WANG}^{1}$, and Hao $\mathrm{YANG}^{1}$ \\ ${ }^{1}$ Hubei Key Laboratory for Heavy Rain Monitoring and Warning Research, Institute of Heavy Rain, \\ China Meteorological Administration, Wuhan 430205, China \\ ${ }^{2}$ Department of Hydrology and Atmospheric Sciences, University of Arizona, Tucson, Arizona 85721-0011, USA
}

(Received 10 August 2020; revised 24 September 2020; accepted 30 September 2020)

\begin{abstract}
Phase Two of the Integrative Monsoon Frontal Rainfall Experiment (IMFRE-II) was conducted over the middle and lower reaches of the Yangtze River during the period 16 June to 19 July 2020. This paper provides a brief overview of the IMFRE-II field campaign, including the multiple ground-based remote sensors, aircraft probes, and their corresponding measurements during the 2020 mei-yu period, as well as how to use these numerous datasets to answer scientific questions. The highlights of IMFRE-II are: (1) to the best of our knowledge, IMFRE-II is the first field campaign in China to use ground-based, airborne, and spaceborne platforms to conduct comprehensive observations over the middle and lower reaches of the Yangtze River; and (2) seven aircraft flights were successfully carried out, and the spectra of ice particles, cloud droplets, and raindrops at different altitudes were obtained. These in-situ measurements will provide a "cloud truth" to validate the ground-based and satellite-retrieved cloud and precipitation properties and quantitatively estimate their retrieval uncertainties. They are also crucial for the development of a warm (and/or cold) rain conceptual model in order to better understand the cloud-to-rain conversion and accretion processes in mei-yu precipitation events. Through an integrative analysis of ground-based, aircraft, and satellite observations and model simulations, we can significantly improve our cloud and precipitation retrieval algorithms, investigate the microphysical properties of cloud and precipitation, understand in-depth the formation and dissipation mechanisms of mei-yu frontal systems, and improve cloud microphysics parameterization schemes and model simulations.
\end{abstract}

Key words: 2020 mei-yu frontal systems, IMFRE-II and its highlights, Comprehensive observations from groundbased, airborne and spaceborne platforms

Citation: Cui, C. G., X. Q. Dong, B. Wang, and H. Yang, 2021: Phase Two of the Integrative Monsoon Frontal Rainfall Experiment (IMFRE-II) over the middle and lower reaches of the Yangtze River in 2020. Adv. Atmos. Sci., 38(3), 346-356, https://doi.org/10.1007/s00376-020-0262-9.

\section{Brief summary of IMFRE-II}

Phase Two of the Integrative Monsoon Frontal Rainfall Experiment (IMFRE-II) was conducted over the middle and lower reaches of the Yangtze River during the period 16 June to 19 July 2020. During IMFRE-II, ten heavy rainfall events occurred and were observed by seven ground-based observational systems, the Shanxi KingAir (KA350) aircraft, and Fengyun and global precipitation measurement (GPM) satellites. The primary goal of IMFRE-II is to investigate the spatiotemporal evolution of mei-yu frontal systems, such as their horizontal and vertical distributions, from west to east over the middle and lower reaches of the Yangtze River through comprehensive observations from ground-based and spaceborne passive and active remote sensors, and aircraft in-situ measurements, as well as model simulations.

IMFRE-II was motivated by IMFRE-I, which was conducted from 10 June to 10 July 2018 over the middle reaches of the Yangtze River and organized by the Wuhan Institute of Heavy Rain (IHR). IMFRE-I maximized the use of our observational capacity enabled by a suite of ground-based remote sensing instruments, most notably the IHR Mesoscale Heavy Rain-

\footnotetext{
* Corresponding author: Xiquan DONG

Email: xdong@arizona.edu
} 
fall Observing System (MHROS), including different wavelengths of radars, microwave radiometers, and disdrometers. The KA350 aircraft participating in the campaign is equipped with Ka-band cloud radar and different probes. The comprehensive datasets from both the MHROS and aircraft instruments are combined with available satellite observations and model simulations to answer the three scientific questions proposed in IMFRE-I.

The 2020 mei-yu season was an extreme one-its rainfall intensity and coverage broke records. The heavy precipitation events during the 2020 mei-yu season can be briefly summarized by the following three characteristics.

\subsection{Stronger rainfall intensity and larger areal coverage over a longer period}

The 2020 mei-yu season over the Yangtze River basin (Hubei) started on 8 June and ended on 21 July, which is eight days earlier and 11 days later than its climatological mean start date (16 June) and end date (10 July), respectively. The 2020 mei-yu season lasted for 44 days, which is 19 days longer than the climatological mean, and ranks as the eighth longest mei-yu season since 1951. During the 2020 mei-yu season, the rainfall centers were primarily located over the middle and lower reaches of the Yangtze River. Some regions, such as southern Chongqing, eastern Hubei, northern Hunan, northwestern Jiangxi, central and southern Anhui, central and southern Jiangsu, and northern Zhejiang, received more than $600 \mathrm{~mm}$ rainfall, which is $50 \%$ higher than normal years. The accumulated rainfall amounts along the Yangtze River were twice as much as or even more than their climatological means. Total rainfall amounts in the southern and central-eastern parts of Hubei Province and the central and southern parts of Anhui Province exceeded $1000 \mathrm{~mm}$ (Fig. 1). The major rainbelt was located in the Yangtze River-Huaihe River valley in early June, shifted southward from middle and late June to early July, and maintained steadily along the Yangtze River and over its northern part. In mid-July, the rainbelt was primarily located over the Yangtze River with slight meridional fluctuation.

Statistical results of precipitation observed at 735 national weather stations in the Yangtze River basin show that the accumulated precipitation amount during the 2020 mei-yu season exceeded $200 \mathrm{~mm}$ over the entire basin (except for a few areas in the middle and upper reaches of the Jinsha River). The regional average precipitation amount during the 2020 mei-yu season over the middle and lower reaches of the Yangtze River was $435.1 \mathrm{~mm}$, which is the largest one since 1961. The second largest precipitation amount is $382.7 \mathrm{~mm}$ in 2016 . Note that the 60 -yr average precipitation amount during the same period is $263.1 \mathrm{~mm}$. The average number of heavy rainfall days in 2020 was 2.3 days/station, the highest one during the same period since 1961

\subsection{More precipitation events with extremely heavy rainfall}

During the 2020 mei-yu season, the Yangtze River basin experienced a total of ten precipitation events, mostly along
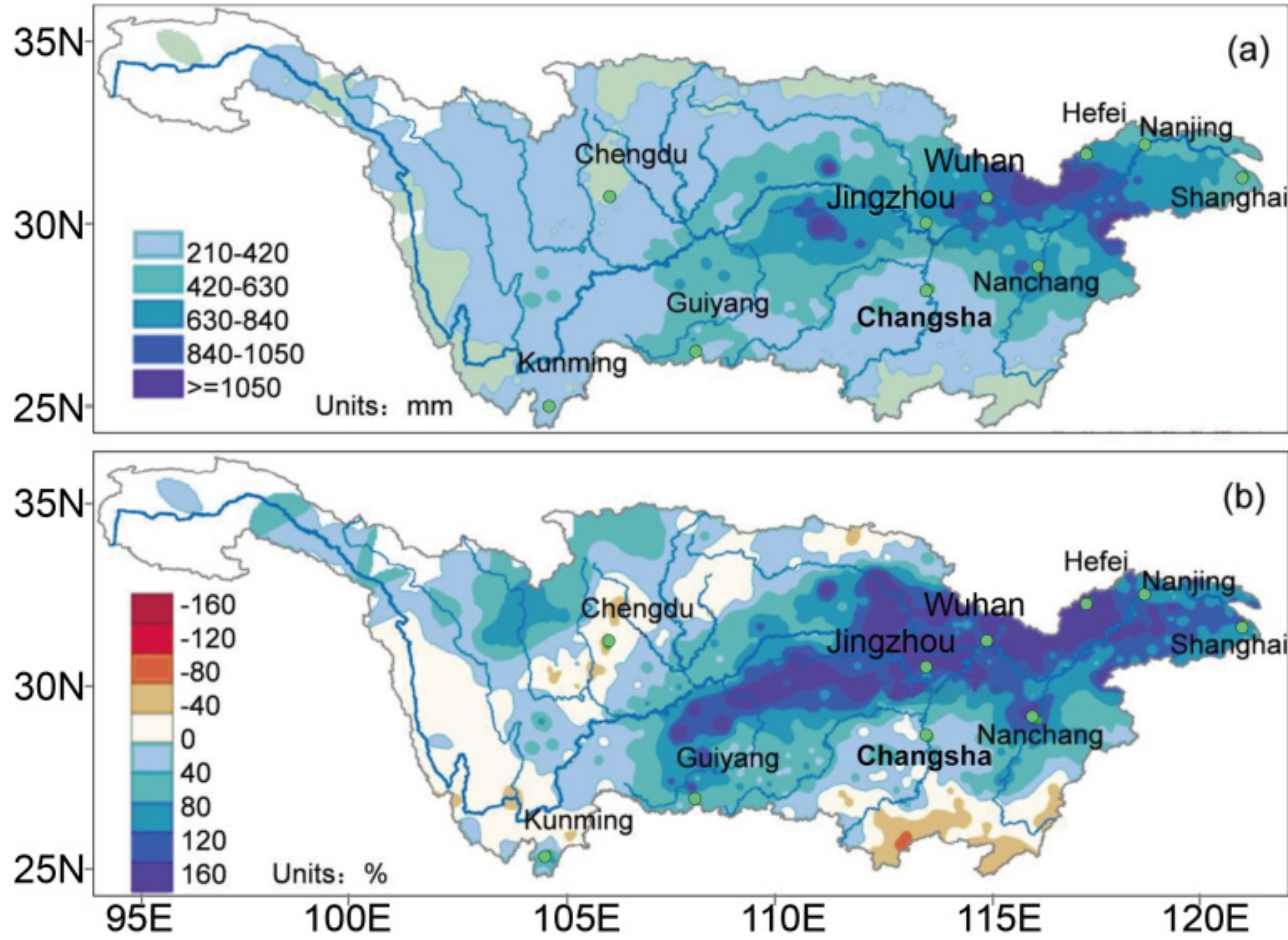

Fig. 1. Spatial distributions of (a) the 2020 mei-yu cumulative precipitation (units: $\mathrm{mm}$ ) and (b) the precipitation anomaly (units: \%) against the climatological mean during the period 8 June to 20 July 2020 in the Yangtze River basin. 
or near the Yangtze River. Table 1 lists the time periods and regions of these ten precipitation events, as well as their highest rainfall for each event, where quite a few regions experienced repeatable heavy precipitation events. Short-term torrential rainstorms frequently occurred during the 2020 mei-yu season. For example, on 6 July 2020, 3-h cumulative rainfall of $178.5 \mathrm{~mm}$ during 0000-0300 LST (LST=UTC+8) and 24-h cumulative rainfall of $502 \mathrm{~mm}$ were observed at Jingzhou, Hubei Province; 6-h cumulative rainfall of $309.4 \mathrm{~mm}$ during 0000-0600 LST and 24-h cumulative rainfall of $436 \mathrm{~mm}$ were observed at Wuhan, Hubei Province; and 24-h cumulative rainfall of $993.9 \mathrm{~mm}$ occurred at Huanggang, Hubei Province. The accumulated rainfall amounts at these three stations all broke their historical records since the establishment of these stations. In addition, several extreme weather events occurred during the 2020 mei-yu season. For example, EF2 tornadoes struck Yangzhou, Jiangsu Province at 1400 LST 12 June and Jingmen in Hubei Province at 1900 LST 27 June.

These extreme heavy rainfall events have caused severe damage to property, threatened human lives, and disrupted daily life with urban and rural flooding, mountain torrents, landslides, and other geological disasters in many places. For instance, the national college entrance exam in Shexian of Anhui Province was delayed due to severe flooding. At 0000 LST 12 July, the water level of Poyang Lake reached 22.53 m, exceeding the 1998 water level and breaking the historical record since the availability of hydrological observations.

\subsection{Anomalous large-scale synoptic and dynamic patterns}

The anomalous large-scale synoptic and dynamic patterns are one of the main factors that led to the extremely heavy rainfall events during the 2020 mei-yu season. The western Pacific subtropical high (WPSH) ridge line was located $10^{\circ}$ west of its normal position and was stronger than normal years, as illustrated in Figs. 2a and b. The southwesterlies in the middle and lower troposphere (i.e., the low-level jet, LLJ) were much stronger than in normal years over the southern part of the Yangtze River (Figs. 2a and b). Significant convergences of both wind direction and wind speed developed over the middle and lower reaches of the Yangtze River. Huge amounts of water vapor were transported by the LLJ from the southwest to the northeast on the west side of the WPSH and converged with the dry and cold air masses transported from the north over the middle and lower reaches of the Yangtze River. The strong convergence of water vapor flux in this region provided anomalously high moisture content (Figs. 2c and d) and eventually resulted in extremely severe rainstorms during the 2020 meiyu period.

\section{Scientific and technical objectives of IMFRE-II}

Mei-yu frontal precipitation is a result of interactions between multi-scale convective systems, such as meso- $\beta$-scale (20-200 km) and meso- $\gamma$-scale $(2-20 \mathrm{~km})$ convective systems. Conventional observations cannot provide the detailed spatial and temporal variations of these multi-scale convective systems, as well as their cloud structures and microphysical processes and properties. Therefore, it is necessary to use newly developed instruments and remote sensors (ground- and satellite-based), as well as aircraft, to provide reliable observations of cloud and precipitation processes and properties at different stages of mei-yu frontal systems and different altitudes in clouds. Only through an integrative analysis of the comprehensive observations from different platforms can we obtain reliable macro- and microphysical properties of clouds and precipitation along the mei-yu frontal systems, as well as their associated thermodynamic and dynamic variables. These comprehensive datasets will pave the way for us to investigate the formation and dissipation processes and mechanisms of mei-yu frontal systems. These datasets are also crucial for us in modifying the current existing microphysics schemes and possibly

Table 1. Brief summary of the 10 precipitation events during the 2020 mei-yu period in the Yangtze River basin.

\begin{tabular}{|c|c|c|c|}
\hline Order & Period & Heavy rainfall area & $\begin{array}{l}\text { Maximum precipitation and } \\
\text { occurrence site }\end{array}$ \\
\hline 1 & 8-11 June & Wujiang River, Dongting Lake, Poyang Lake, Hanjiang River & Sile, Hunan, $252.1 \mathrm{~mm}$ \\
\hline 2 & 11-14 June & Both banks of the top and lower reaches of the Yangtze River & Gao Jiana, Hunan, 353 mm \\
\hline 3 & 15-18 June & $\begin{array}{l}\text { Jianglingjiang River, Wujiang River, and the lower reaches of the Yangtze } \\
\text { River }\end{array}$ & Changping, Sichuan, $333 \mathrm{~mm}$ \\
\hline 4 & 20-25 June & $\begin{array}{l}\text { Hanjiang River, Wujiang River, Poyang Lake and the lower reaches of the } \\
\text { Yangtze River }\end{array}$ & Shendu, Hunan, $403.5 \mathrm{~mm}$ \\
\hline 5 & 26-30 June & The top and lower reaches of the Yangtze River & Huaban, Sichuan, $906.1 \mathrm{~mm}$ \\
\hline 6 & 1-4 July & $\begin{array}{l}\text { The top and lower reaches of Jinsha River, Wujiang River, Poyang Lake and } \\
\text { the top reaches of Yangtze River }\end{array}$ & Yutang, Jiangxi, $311.2 \mathrm{~mm}$ \\
\hline 7 & 4-8 July & The top and lower reaches of the Yangtze River & Bahe, Hubei, 993.9 mm \\
\hline 8 & 9-12 July & Jialing River, Wujiang River Basin, Dongting Lake, Poyang Lake & Yonghe, Jiangxi, $480.9 \mathrm{~mm}$ \\
\hline 9 & 14-17 July & The upper and lower reaches of the Yangtze River & $\begin{array}{l}\text { Hong Chiba, Chongqing, } \\
441.9 \mathrm{~mm}\end{array}$ \\
\hline 10 & 17-19 July & The top and lower reaches of the Yangtze River & Sungang, Anhui, $414.8 \mathrm{~mm}$ \\
\hline
\end{tabular}



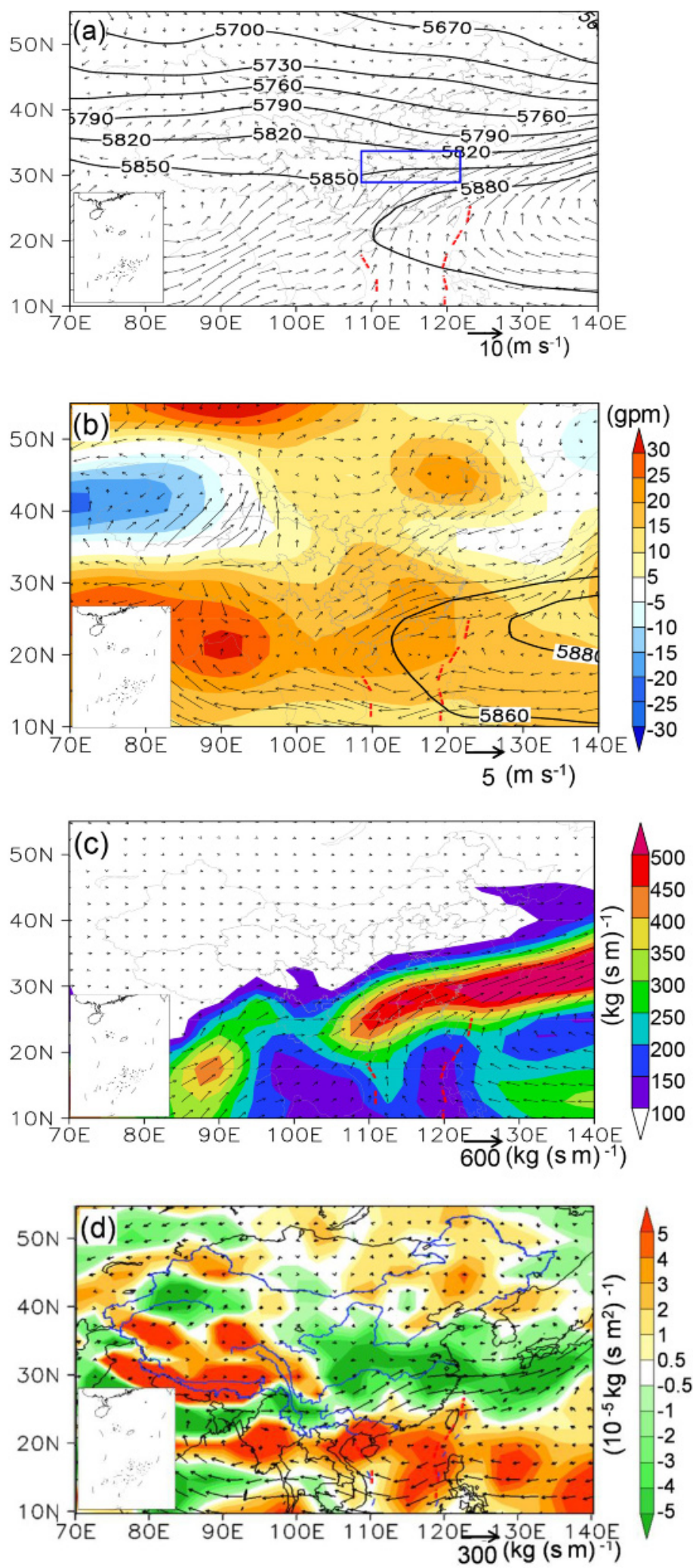

Fig. 2. (a) 500-hPa mean geopotential height ( $\mathrm{GH}$, contours), $850-\mathrm{hPa}$ mean winds (vectors) and (c) integrated moisture flux (vectors and shading) derived from NCEP reanalysis during the 2020 mei-yu season (8 June to 20 July 2020) and (b, d) their anomalies (relative to the climatological mean for the period 1981-2010; shaded). The contours in (c) are the averaged GH for the period 1981-2010. The blue box in (a) is the IMFRE-II field region. 
develop new ones that are suitable for simulating the mei-yu rain events along the Yangtze River and improve the accuracy of model forecasts.

Through comprehensive observations and numerical modeling simulations, we aim to achieve the following scientific goals during the IMFRE-II field campaign: (1) investigate the dynamic and thermodynamic structures of the mesoscale systems embedded in the mei-yu frontal system and explore the hydrometeor and microphysical characteristics of cloud clusters conducive to rainstorms; (2) reveal the roles of the moisture transported from the southwest and environmental conditions on the formation and development of clouds and precipitation; (3) through comparing the similarities and differences of the mei-yu frontal systems between the middle and lower reaches of the Yangtze River, we will eventually build a conceptual model in order to better characterize the formation mechanisms and spatiotemporal evolution of mei-yu frontal systems over the middle and lower reaches of the Yangtze River.

Based on IMFRE-I and -II, as well as follow-up field campaigns, we will also address the following three key technical issues: (1) how to spatially and temporarily match different observations from ground-based and spaceborne remote sensors and aircraft probes and how to quantitatively estimate ground-based and satellite observations and retrievals using aircraft in-situ measurements; (2) how to use the aircraft measured spectra of ice particles, cloud droplets, and raindrops at different altitudes of clouds to develop a warm (and/or cold) rain conceptual model in order to better understand the cloud-torain conversion and accretion processes in mei-yu precipitation events; (3) how to quantitatively evaluate the applicability of various cloud microphysics schemes to mei-yu frontal systems using these comprehensive datasets.

\section{Design and layout of the IMFRE-II field campaign}

\subsection{Experimental area}

IMFRE-II was organized by the Wuhan Institute of Heavy Rainfall, China Meteorological Administration, with joint efforts from the University of Arizona, Georgia Institute of Technology, University of Science and Technology of China, Nanjing University, Jiangsu Meteorological Bureau, Anhui Institute of Meteorological Sciences, Shanxi Weather Modification Office, and Hubei Meteorological Bureau. There are seven surface sites in the middle and lower reaches of the Yangtze River and their locations are shown in Figs. 3 and 4. Four surface sites are located in the middle reaches of the Yangtze River (Zone I in Fig. 4) and the other three sites are located in the lower reaches (Zone II in Fig. 4). The ground-based remote sensors and instruments at each surface site, and the aircraft probes, are introduced as follows.

\subsection{Ground-based observational system}

The ground-based observations include those obtained from MHROS, with additional observations from traditional weather radars, regular soundings, and surface meteorological variables located at the four surface sites in Hubei Province (Zone I in Fig. 4). IHR MHROS consists of mobile X-POL precipitation radars, millimeter wavelength cloud radars, fixed S-band dual-polarimetric precipitation radars, micro-rain radars, GNSS/MET network, microwave radiometers, radiosonde soundings, wind profiler radars, and Parsivel and 2DVD disdrometers. The other three surface sites in Zone II have similar instruments as IHR MHROS, but not all. The surface remote sensors and instruments at each site used in this study are listed in Table 2.

\subsection{Aircraft probes and flight plan}

The KA350 aircraft participating in the IMFRE-II field campaign is equipped with the following sensors: cloud particle probe (CDP), cloud imaging probe (CIP), and precipitation imaging probe (PIP) for measuring cloud and precipitation droplet size distributions; PCASP and CCN-200 for measuring aerosol properties and cloud condensation nuclei; Ka-band cloud radar for measuring cloud and light precipitation with a total of 17 flight hours during IMFRE-II (Table 3). The aircraft was based out of the Yichang Three Gorges International Airport (denoted by the yellow triangle in Fig. 4), which is $104 \mathrm{~km}$ away from the Jingzhou surface site. The flight area is a grid box of $10 \mathrm{~km} \times 10 \mathrm{~km}$ centered at the Jingzhou surface site (site 3 and yellow rectangular area in Fig. 4). Figure 5 illustrates some probes and cloud radar aboard the KA350 aircraft.

The KA350 aircraft flew primarily in horizontal flight patterns at different altitudes with one to two vertical flights. Specifically, after taking off, the aircraft ascended to the cloud top or a maximum height of $7300 \mathrm{~m}$ and then circled around over the targeted area. It maintained a steady, horizontal flight pattern at the highest altitude and then descended $300 \mathrm{~m}$ for another horizontal circular flight. The aircraft repeatedly passed through the clouds at different altitudes until it reached a minimum altitude of $1500 \mathrm{~m}$ and then climbed up to $7300 \mathrm{~m}$.

\section{Highlights of IMFRE-II}

IMFRE-II was conducted over the middle and lower reaches of the Yangtze River during the period 16 June to 19 July 


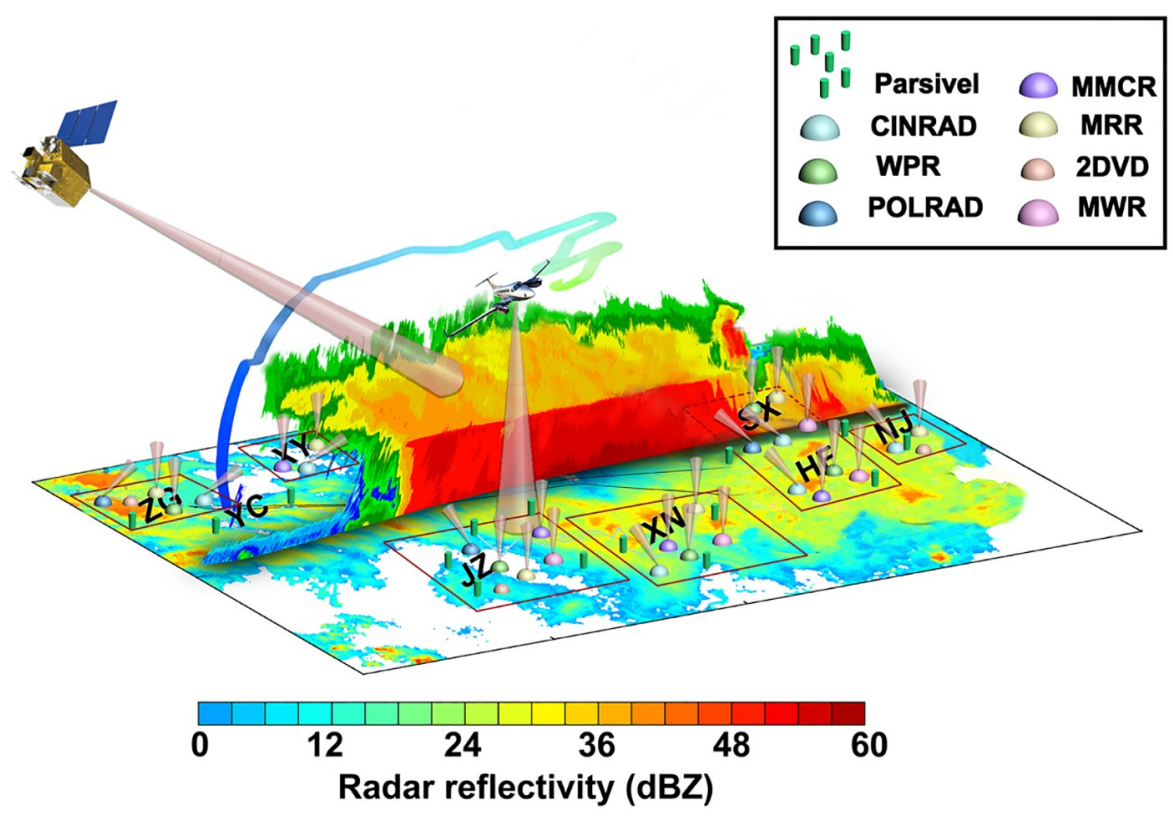

Fig. 3. Schematic diagram showing seven surface sites, satellite and aircraft observations during the IMFRE- II field campaign during the period June-July 2020 over the middle and lower reaches of the Yangtze River. The abbreviations represent the names of the seven surface as follows: ZG, Zigui; XY, Xiangyang; JZ, Jingzhou; XN, Xianning; SX, Shouxian; HF, Hefei; NJ, Nanjing. In addition, YC denotes Yichang airport, where the aircraft takes off and lands.

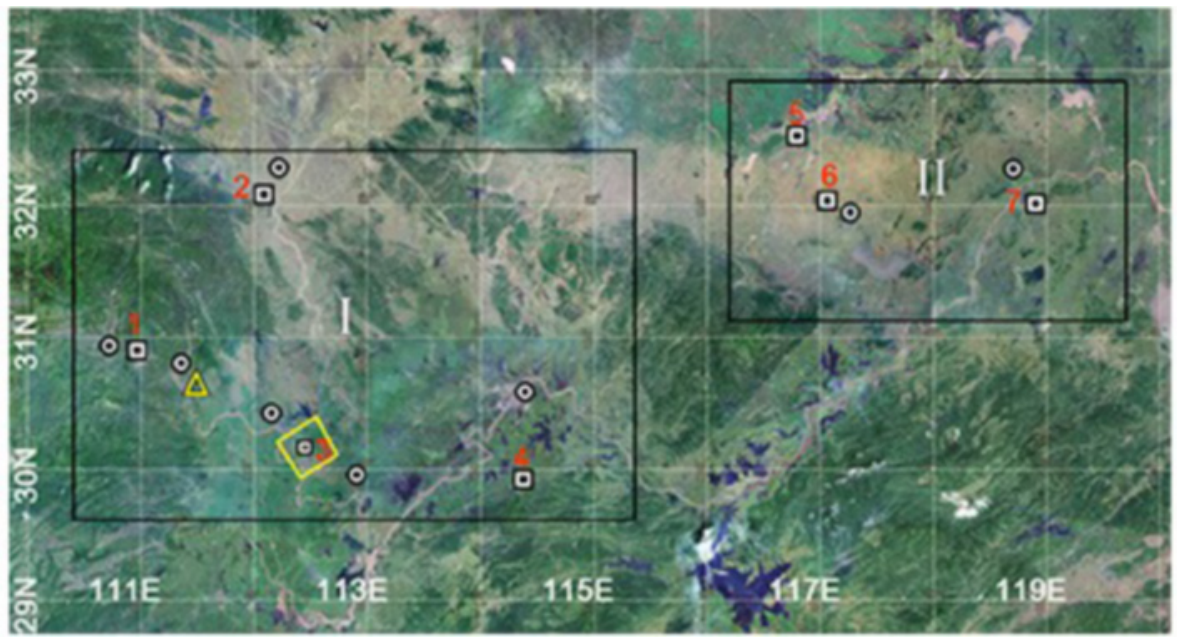

Fig. 4. Layout of the surface sites and the airport during IMFRE- II over the middle and lower reaches of the Yangtze River. The squares indicate the locations of the seven surface sites, with the numbers 1-7 representing Zigui, Xiangyang, Jingzhou, Xianning, Shouxian, Hefei, and Jiangning, respectively. The circular marks indicate the locations of precipitation weather radars, the yellow triangle represents Yichang airport, and the yellow rectangle indicates the flight area (over the Jingzhou surface site). The numbers I and II represent observing target areas in the middle and lower reaches of the Yangtze River, respectively.

2020. During IMFRE-II, 10 mei-yu frontal systems were observed by different platforms, including both ground-based and spaceborne active and passive remote sensors, KA350 probes, and onboard cloud radar. A large amount of remote sensing observations and in-situ measurements related to heavy rainfall processes and properties during the mei-yu period were obtained. Some highlights from IMFRE-II are presented as follows:

(1) To the best of our knowledge, IMFRE-II is the first field campaign in China to use ground-based, airborne, and spaceborne platforms to obtain comprehensive observations over the middle and lower reaches of the Yangtze River. Seven ground-based observational systems, such as MHROS, with the addition of traditional weather radars, regular soundings, 


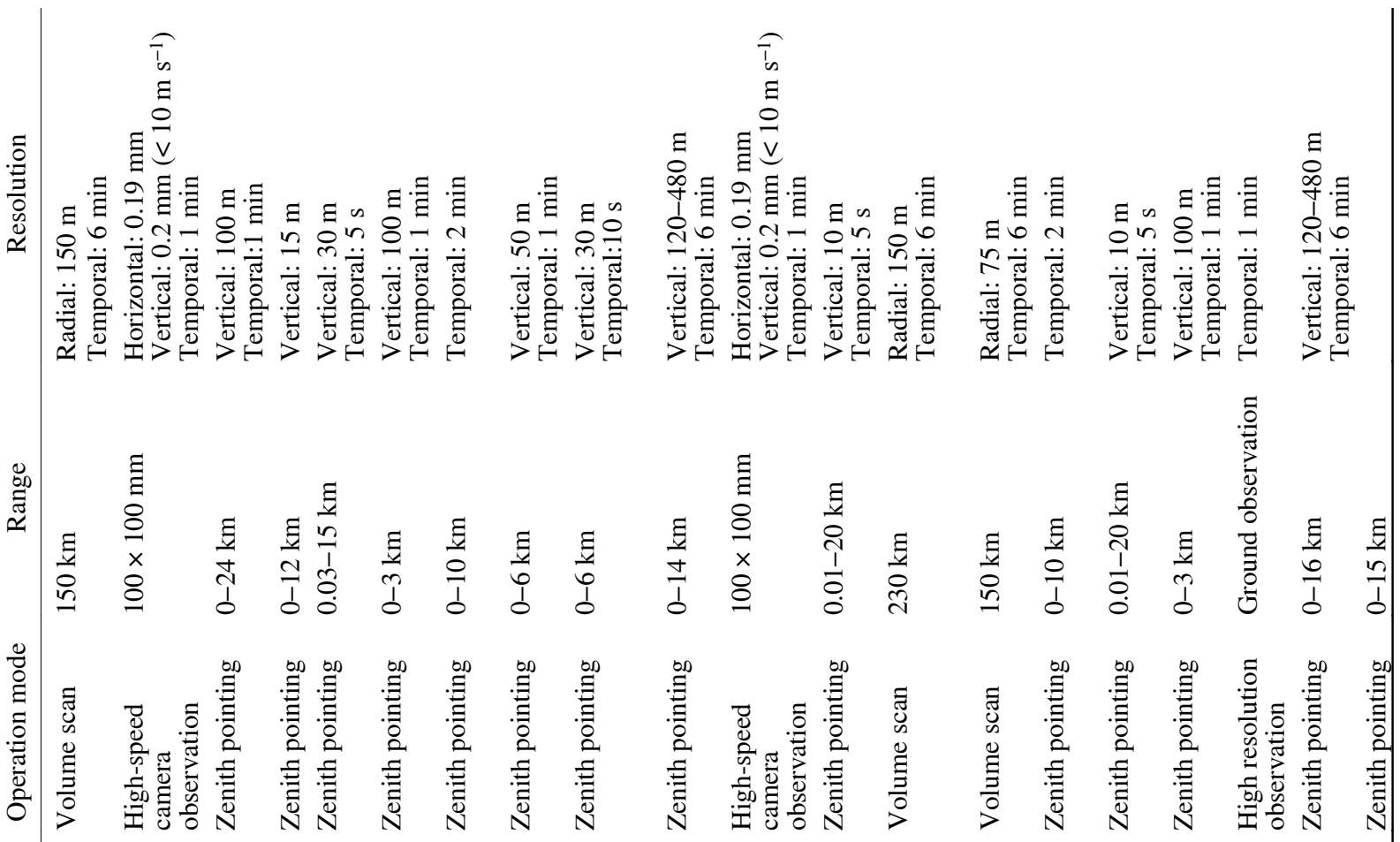

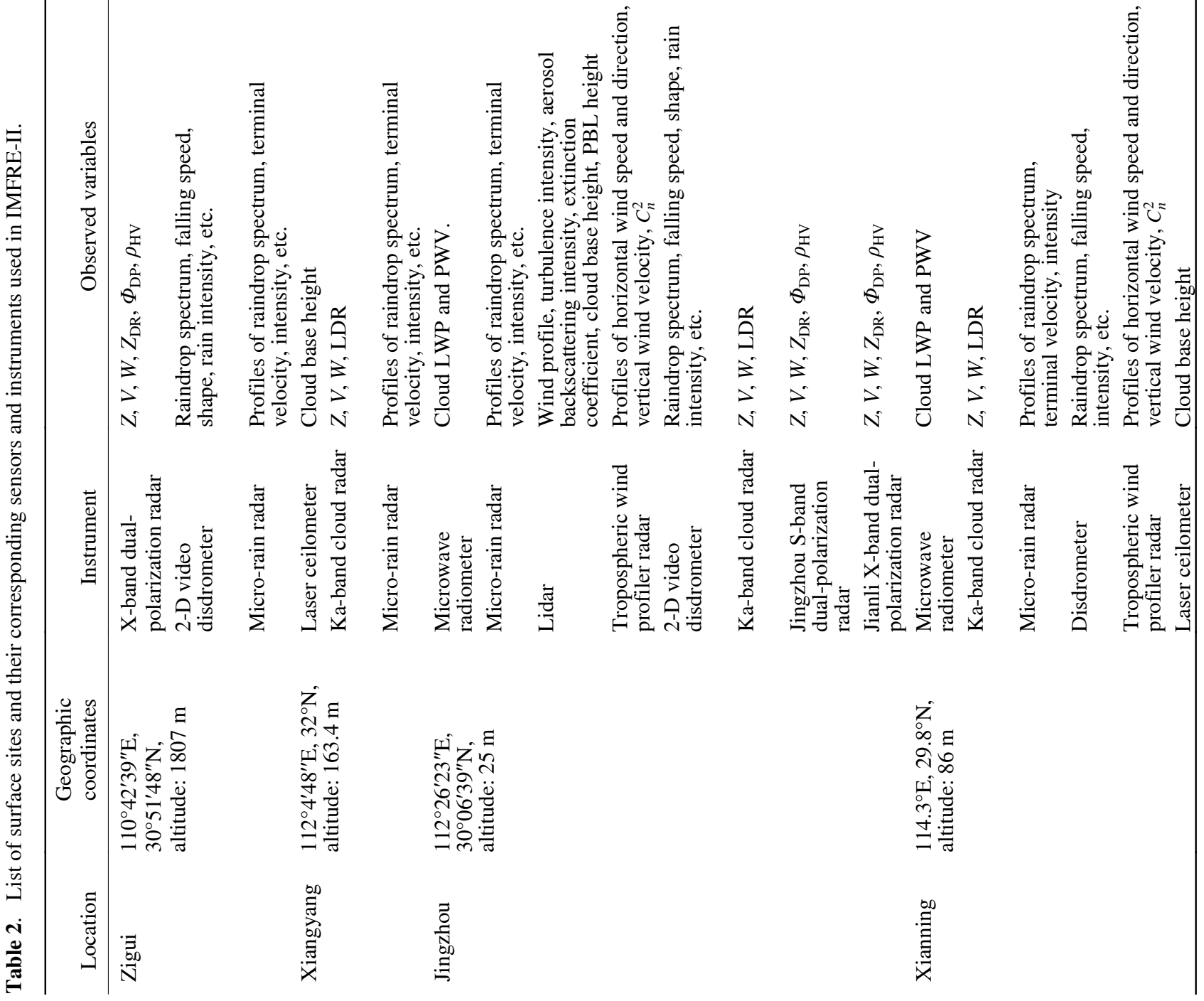




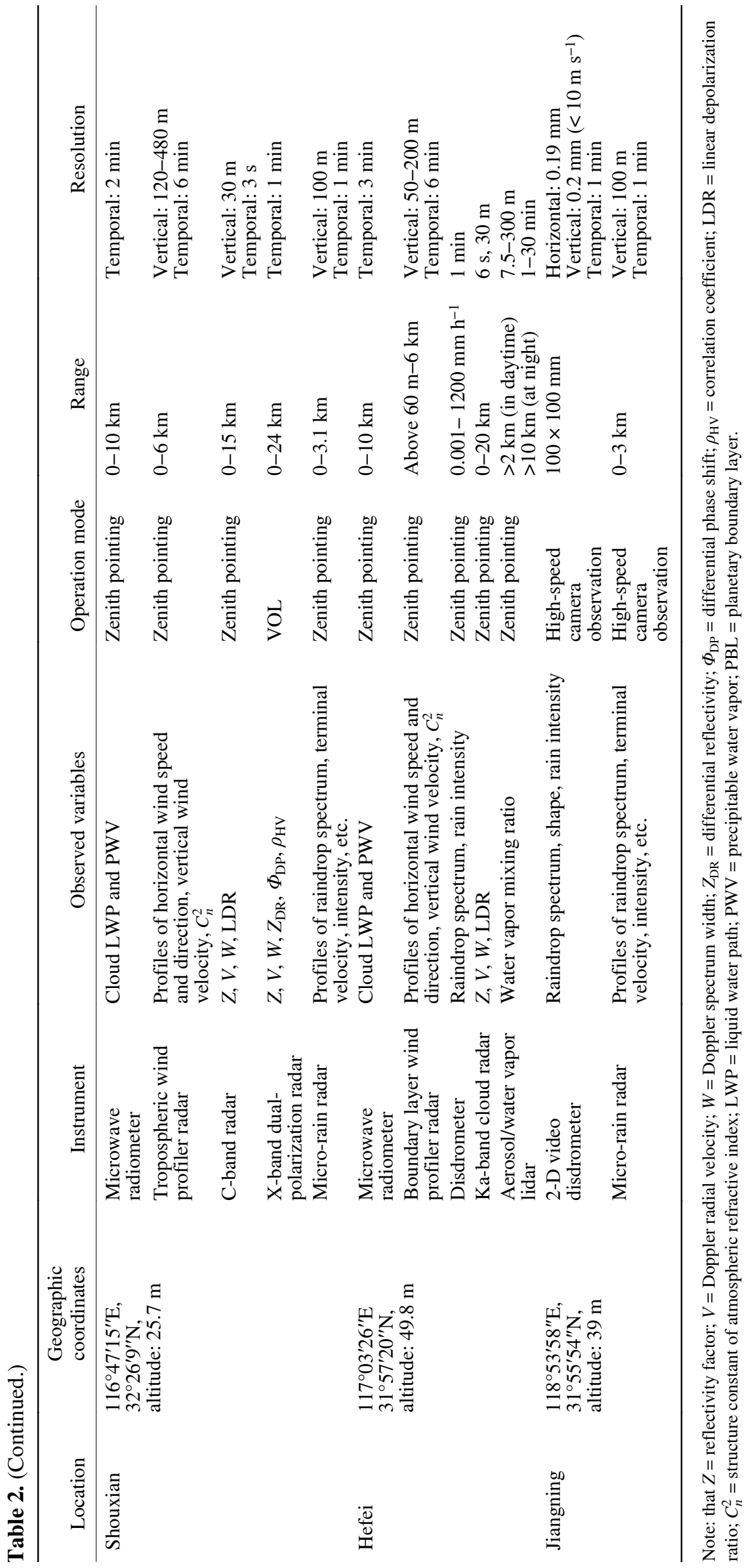


Table 3. KingAir probes and Ka-band cloud radar.

\begin{tabular}{cccc}
\hline Name & Detecting range $(\mu \mathrm{m})$ & Number of channels & Cloud parameters \\
\hline CDP (cloud particle probe) & $2-50$ & 30 & Cloud droplets, ice crystals \\
CIP (cloud imaging probe) & $12.5-1562.5$ & 62 & Large cloud droplets, snow and ice crystals \\
PIP (precipitation imaging probe) & $50-6250$ & 62 & Precipitation particles, sleet, snow and ice crystals \\
PCASP & $0.095-3.1$ & 30 & Aerosols \\
CCN-100 & $0.25-10.25$ & 20 & Cloud condensation nuclei \\
AIMMS & & & Temperature, pressure, humidity, winds, etc. \\
KPR (Ka-band cloud radar) & -35 to $35 \mathrm{dBZ}$ & & Cloud, light precipitation \\
WCM (total water content) & $10^{-4}$ to $10 \mathrm{~g} \mathrm{~m}^{-3}$ & & Clouds and precipitation \\
\hline
\end{tabular}

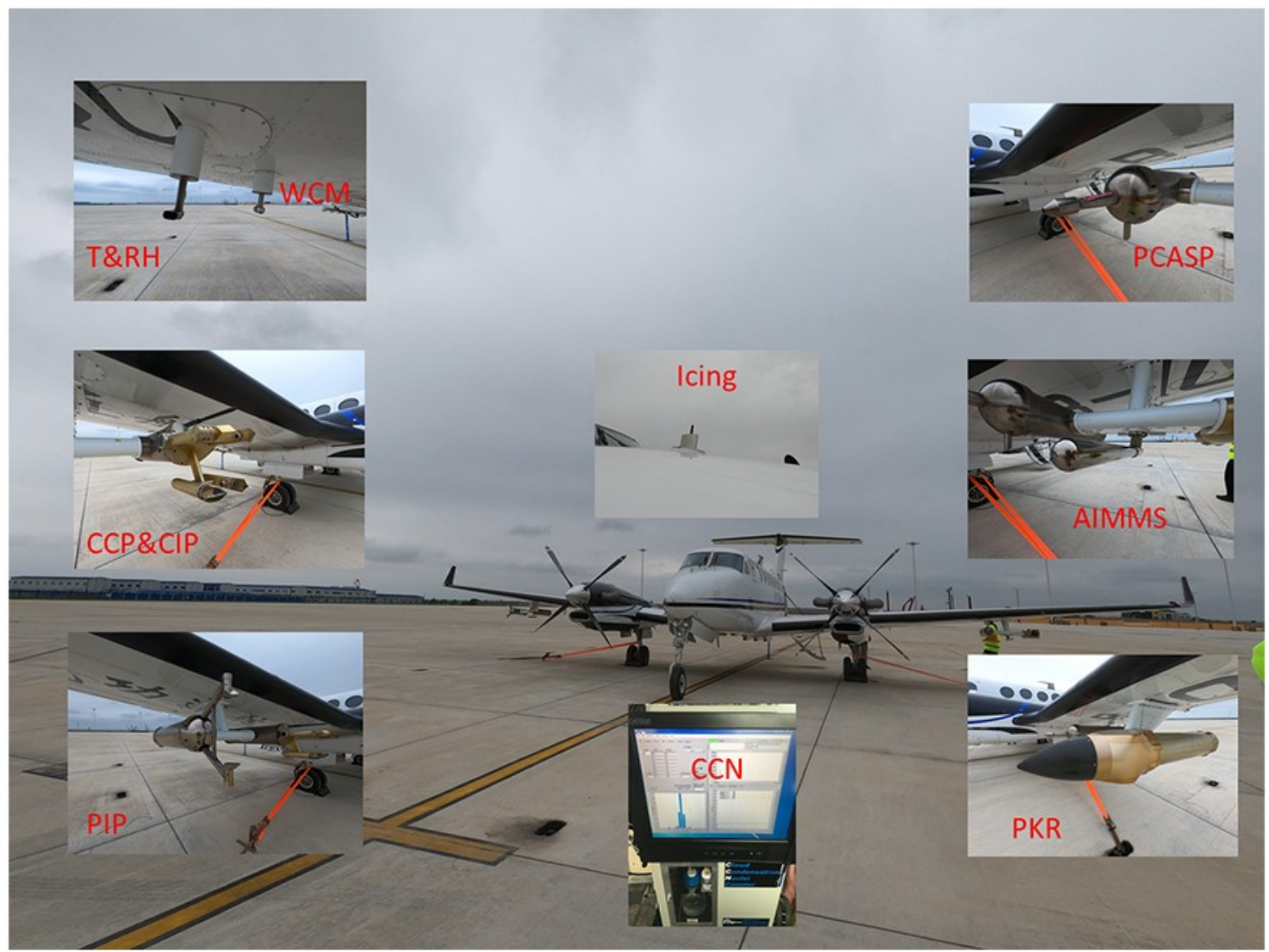

Fig. 5. Photos of the Shanxi KingAir aircraft probes and onboard Ka-band cloud radar (PKR).

and surface meteorological variables, were used to collect data related to heavy rainfall processes during the mei-yu period. These ground-based observations combined with Fengyun and GPM satellite observations can provide the horizontal and vertical distributions of rainfall processes and properties, which are crucial in studying the spatiotemporal evolution of mei-yu frontal systems from west to east over the middle and lower reaches of the Yangtze River. The microphysical properties of cloud and precipitation were observed and retrieved from the active and passive ground-based remote sensors and instruments, including different wavelengths of radars, microwave radiometers, and Parsivel and 2DVD disdrometers.

(2) Seven aircraft flights were successfully carried out with a total of 17 hours and the spectra of ice particles, cloud droplets, and raindrops at different altitudes were obtained. Of the seven flights, two were in moderate rain, two were in light rain, and three flew through cloudy and clear-sky conditions. As illustrated in Fig. 6 and listed in Table 4, the KA350 aircraft flew from $\sim 1500 \mathrm{~m}$ to $7300 \mathrm{~m}$ and collected the spectra of ice particles, cloud droplets, and raindrops in clouds at different altitudes. Figure 7 shows an example of Ka-band cloud radar reflectivity onboard the KA350 aircraft and their associated cloud and rain drop size distributions (DSDs) at different altitudes on 21 June 2020 during IMFRE-II. The vertical distributions of radar reflectivity and DSDs have demonstrated a typical warm rain process in a mei-yu precipitation event. Cloud droplets normally grow with height through the condensational process in updrafts and become rain-sized drops through the collision-coalescence and autoconversion processes near the cloud top. These raindrops fall from near the 


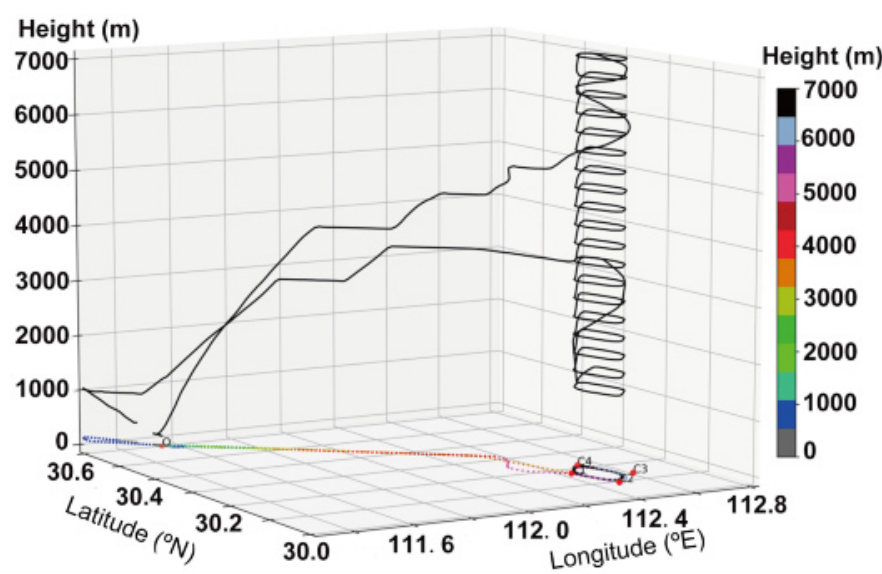

Fig. 6. A sample of the aircraft flight track on 18 June 2020 over the Jingzhou surface site.

Table 4. Summary of the aircraft flights during IMPFRE-II.

\begin{tabular}{ccccccc}
\hline Order & Date & $\begin{array}{c}\text { Measurement } \\
\text { period (LST) }\end{array}$ & $\begin{array}{c}\text { Minimum flight } \\
\text { altitude }(\mathrm{m})\end{array}$ & $\begin{array}{c}\text { Maximum flight } \\
\text { altitude }(\mathrm{m})\end{array}$ & $\begin{array}{c}\text { Freezing level } \\
\text { altitude }(\mathrm{m})\end{array}$ & Weather \\
\hline 1 & 18 June & $1040-1240$ & 1499 & 7335 & 5420 & Rainy \\
2 & 21 June & $1845-1955$ & 3075 & 7318 & 5782 & Rainy \\
3 & 28 June & $1510-1705$ & 1463 & 6326 & 5668 & Rainy \\
4 & 1 July & $0940-1140$ & 1511 & 7326 & 5426 & Cloudy \\
5 & 2 July & $1825-2025$ & 1480 & 7339 & 5355 & Clear sky \\
6 & 4 July & $1050-1205$ & 4723 & 7331 & 5638 & Rainy \\
7 & 4 July & $1640-1758$ & 1492 & Clear sky \\
\hline
\end{tabular}
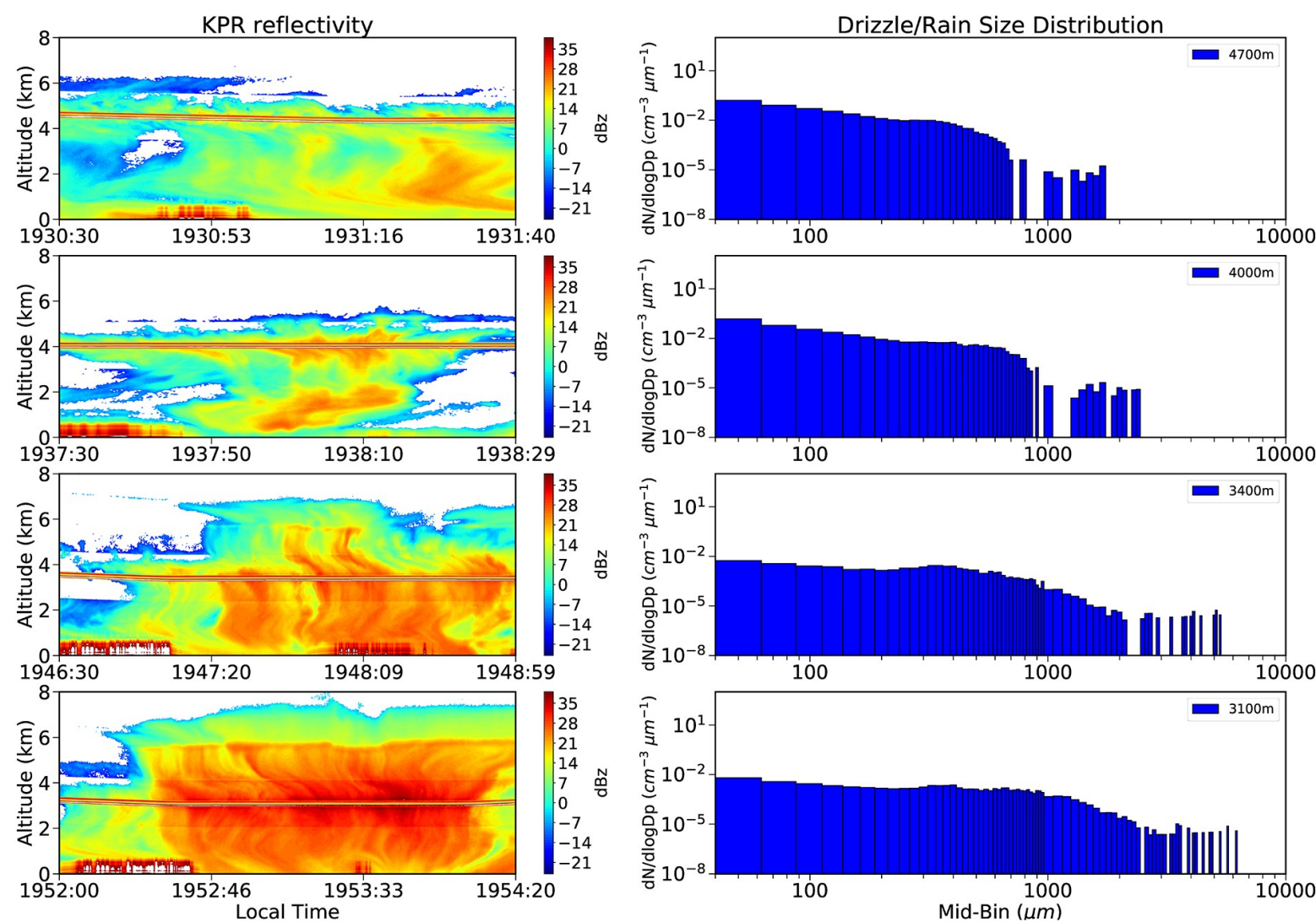

Fig. 7. Left-hand column: Ka-band $(35.64 \mathrm{GHz})$ cloud radar reflectivity onboard the KingAir aircraft during four time periods at different altitudes with a descending mode on 21 June 2020 over the Jingzhou surface site during IMFRE-II. Right-hand column: The corresponding cloud and rain drop size distributions (DSDs) from the merged product of CDP $(2-50 \mu \mathrm{m})$, CIP $(25-1550 \mu \mathrm{m})$ and PIP $(100-6200 \mu \mathrm{m})$ during the four times and altitudes. 
cloud top where the gravitational force exceeds the buoyancy force and grow further by collecting cloud droplets and small raindrops through the collision-coalescence process. As raindrops fall, the spectra of the DSD become wider and the accretion process becomes increasingly important, and eventually some of the raindrops become larger raindrops down to the surface. These in-situ measurements, as well as the onboard cloud radar measurements, will provide a "cloud truth" to validate the ground-based and satellite retrieved cloud and precipitation properties, and quantitatively estimate their retrieval uncertainties. These integrative datasets provide a solid basis for the development of a warm (and/or cold) rain conceptual model in order to better understand the cloud-to-rain conversion and accretion processes in mei-yu precipitation events.

Acknowledgements. The IMFRE-II field campaign was primarily supported by the National Natural Science Foundation of China (Grant Nos. 41620104009 and 91637211), the Key Program for International S\&T Cooperation Projects of China (Grant No. 2016YFE0109400), and the National Key R\&D Program of China (Grant No. 2018YFC1507200). 